\title{
Título do sítio electrónico: Campus Virtual de
} Economia Solidária

URL: http://www.economiasolidaria.net/

Pedro Hespanha

\section{OpenEdition}

\section{Journals}

Edição electrónica

URL: https://journals.openedition.org/rccs/558

DOI: $10.4000 /$ rccs.558

ISSN: 2182-7435

\section{Editora}

Centro de Estudos Sociais da Universidade de Coimbra

Edição impressa

Data de publição: 1 março 2009

Paginação: 201-202

ISSN: 0254-1106

\section{Refêrencia eletrónica}

Pedro Hespanha, «Título do sítio electrónico: Campus Virtual de Economia Solidária», Revista Crítica de Ciências Sociais [Online], 84 | 2009, publicado a 01 outubro 2012, consultado a 21 setembro 2021.

URL: http://journals.openedition.org/rccs/558 ; DOI: https://doi.org/10.4000/rccs.558

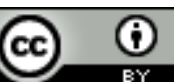




\section{Espaço Virtual}

\section{Título do sítio electrónico: ISTR - The International Society for Third-Sector Research URL: http://www.istr.org/}

A ISTR é uma das principais associações internacionais para a promoção da investigação e do ensino nos campos da filantropia, sociedade civil e sector não lucrativo, reflectindo o crescente interesse pelo estudo do terceiro sector e constituindo um fórum permanente para o debate e a investigação internacional neste campo. Criada em 1992, a ISTR é hoje reconhecida pela sua visão global, pelo seu compromisso com a excelência, pela sua atitude de cooperação e pelos valores de diversidade e pluralismo que orientam a sua acção. Procurando promover e facilitar a participação dos investigadores de todo o mundo, uma particular atenção é dada aos países da Europa Central e de Leste e ao papel do terceiro sector nessa região.

A quem acede o site pela sua página de entrada, surge com o maior destaque o anúncio da próxima Conferência Internacional do ISTR, a $9^{a}$ desde a sua fundação, desta vez sobre os desafios que a crise coloca ao terceiro sector: Facing Crises: Challenges and Opportunities Confronting the Third Sector and Civil Society. Informação sobre as conferências anteriores pode ser igualmente obtida no link "Conferences" na barra de menus ao cimo da página e também no link "Publications", onde se encontram à disposição seis volumes com os working papers apresentados desde a terceira conferência. Este último link remete o utilizador para um vasto e especializado acervo de publicações, incluindo a Revista Voluntas (com índice e resumos de todos os artigos publicados desde o início - 1990), a Newsletter da ISTR (em versão integral desde 2002) e os seus relatórios anuais. Uma última referência para um documento intitulado ISTR Strategic Directions, que estabelece a estratégia de acção da Sociedade para o período de 2005-2009. De realçar, finalmente, uma outra barra de menus (à esquerda) que contém um calendário de eventos, informação sobre as redes regionais da ISTR (África, Ásia-Pacífico, Europa e América Latina e Caraíbas), um espaço para os grupos de interesses afins (que agregam estudiosos do terceiro sector de acordo com critérios geográficos, disciplinares ou temáticos (vg. AGG - Affinity Group on Gender) e uma plataforma para comunicação com os membros do ISTR e outras pessoas interessadas em trocar informação, pontos de vista e notícias sobre o terceiro sector ou, simplesmente, envolverem-se em conversação.

\section{Título do sítio electrónico: EMES European Research Network URL: http://www.emes.net}

A Rede EMES deve o seu nome ao primeiro programa de investigação realizado por ela sobre a emergência das empresas sociais na Europa. O subtítulo da Rede é mais claro sobre os seus objectivos: "construir conhecimento sobre a economia social e o empreendedorismo social na Europa”. Em geral, ela estuda as organiza- 
ções do terceiro sector que, embora cada vez mais importantes na Europa e em toda a parte, ainda são mal conhecidas e estudadas. No caso, o conceito amplo de terceiro sector integra designações tão diversas como economia social, economia solidária, sector não lucrativo, organizações de voluntariado e empresas sociais. A investigação da EMES centra-se principalmente na realidade europeia e difere um tanto da que é feita em outros continentes, devido sobretudo à história das instituições e das políticas europeias. Porém, o contacto com parceiros internacionais como a ISTR e a RILESS ( $v d$. infra) tem levado a uma reflexão muito produtiva sobre as teorias e os conceitos que orientam a investigação em diferentes áreas geográficas do globo. A EMES associa instituições e indivíduos que fazem investigação multidisciplinar de alto nível sobre a diversidade do terceiro sector e sobre o modo como as empresas e as organizações do terceiro sector se integram nas respectivas sociedades. Simultaneamente, a Rede procura introduzir nas Universidades, como campo de ensino ou material de estudo, o tema do terceiro sector bem como disseminar os resultados da investigação através de publicações e da organização de colóquios tais como a "First European ISTR-EMES Conference: Concepts of the Third Sector", realizada em 2005.
Da página de entrada, acede-se facilmente aos vários conteúdos quer através de um útil sitemap quer de um potente motor de busca.

A identificação dos campos de pesquisa da EMES é acompanhada de uma curta apresentação do campo a cargo de académicos ou centros reputados: Adalbert Evers ("Terceiro Sector"), Jacques Defourny ("Economia Social"), Jean-Louis Laville ("Economia Solidária"), Johns Hopkins Center for Civil Society Studies ("Economia não lucrativa"). De particular utilidade para quem começa é a secção das publicações que, além de referenciar um conjunto actualizado de obras centrais para o tema, inclui a possibilidade de o utilizador descarregar, sem encargos, vários textos de autores de referência e working papers da investigação própria e conference papers apresentados em encontros organizados pela Rede.

Para quem estiver interessado em estudos avançados nos temas da Rede pode obter informações sobre programas de doutoramento e sobre a Escola de Verão organizada pela própria Rede. Se quiser saber mais sobre organizações internacionais e redes sobre os mesmos temas, tem uma vasta lista de opções com ligações directas para as respectivas páginas.

\section{Título do sítio electrónico: RILESS - Red de Investigadores Latino-ame- ricanos de Economía Social y Solidaria URL: http://www.riless.org/}

Esta Rede tem como pressuposto a possibilidade de construir um outro mundo e defende que a construção deste requer o desenvolvimento de uma economia alternativa. Trata-se de um projecto conjunto do Mestrado em Economia Social (MAES) e URBARED, do Instituto del Conurbano da Universidad Nacional de General Sarmiento (UNGS) - Argentina, do Grupo de Pesquisa sobre Economia Solidária da Cátedra UNESCO/UNISINOS - Brasil e do Programa de Pós-graduação em Economia Social (PES)/FLACSO-Ecuador. Através da URBARED está associado ao pro- 
jecto também o Instituto de Pesquisas Sociais da Universidad Nacional Autónoma do México (UNAM).

O objectivo a que a RILESS se propõe consiste no desenvolvimento de uma rede de investigadores Latinoamericanos que trabalhe dentro de um marco plural, contribuindo para a elaboração de projectos, intercâmbio e outras formas de cooperação e facilitando e promovendo trabalhos multidisciplinares com o fim de fortalecer as iniciativas colectivas para uma outra economia, uma outra sociedade e uma outra política na América Latina.

A página principal destaca as novidades em diferentes campos (Agenda, Biblioteca, Investigadores, Experiências ou Formação) e, ao mesmo tempo, remete para uma vasta e riquíssima lista de entradas, que permitem ao utilizador saber mais sobre o campo; por exemplo, quem são os investigadores em Economia Social e Solidária em toda a América Latina.

À esquerda, uma barra de menus bastante detalhada oferece informação sobre a biblioteca, os investigadores, as experiências, a formação, os conceitos, os movimentos e organizações sociais, os fora, a agenda e o boletim. Chama-se a atenção para alguns destes links, pela sua originalidade e utilidade. Em "conceitos" o utilizador vai encontrar, em forma de dicionário (e semelhante ao Dicionário Internacional da Outra Economia recentemente editado pelo CES), entradas de autor com o essencial sobre cada conceito (vg. associativismo, autogestão, comércio justo) e uma bibliografia básica e ainda um espaço aberto para debate e comentários sobre o tema. $\mathrm{Na}$ secção "experiências" apresentam-se experiências relativas a formas de economia alternativa, passadas ou presentes, com o objectivo de suscitar a análise e o debate acerca, por exemplo, da sua replicabilidade em contextos distintos, da sua contribuição efectiva para a construção de uma outra economia ou do seu potencial inspirador de novas propostas. A secção "formação" informa sobre cursos, oficinas e outras actividades de capacitação no âmbito da economia solidária ou de formas alternativas de empreender que estejam a ser oferecidas algures.

A RILESS edita ainda um Boletim que podes ser recebido regularmente mediante inscrição online.

\section{Título do sítio electrónico: CIRIEC - Centre International de Recherches et d'Information sur l'Economie Publique, Sociale et Coopérative. URL: http://www.ciriec.ulg.ac.be/}

O objectivo do CIRIEC é promover a busca de informações, a investigação científica e a publicação de trabalhos sobre os sectores e actividades que têm por finalidade o interesse geral: poder público, serviços públicos, empresas públicas, cooperativas, sociedades laborais, associações e outras formas de Economia Social. O CIRIEC - Internacional tem sede na Universidade de Liége, na Bélgica, e conta com secções nacionais em 13 países in- cluindo Portugal. No site do CIRIEC Internacional pode-se encontrar informações sobre a entidade e links para as páginas do CIRIEC nos outros países.

A página de entrada destaca a actualidade: presentemente, a realização da $2^{a}$ Conferência Internacional de Investigação em Economia Social, que terá lugar em Outubro de 2009 na Suécia; e do $28^{\circ}$ Congresso Internacional do CIRIEC, em Maio de 2010 em Berlim. Mas também os 100 anos 
dos Annales de l'Economie Publique, Sociale et Cooperative. Uma janela rolante completa a informação sobre acontecimentos próximos e algumas fotos dão conta de acontecimentos ocorridos recentemente. Informação mais substancial consta da barra de menus ao cimo da página. Aí o utilizador pode encontrar informação institucional sobre o CIRIEC, sua missão e história, Secções Nacionais e outros membros. As actividades científicas do CIRIEC são desenvolvidas por uma rede internacional de cerca de 100 especialistas em economia pública, social e cooperativa. Na seç̧ão correspondente da página, o utilizador encontra muita informação sobre a investigação desenvolvida pelo CIRIEC - por exemplo, sobre os métodos e indicadores de avaliação da economia social, sobre a regulação dos serviços públicos num contexto de liberalização e de concorrência aberta, ou sobre temas mais transversais como os regimes de governação nos serviços sociais e de saúde - ou encomendada ao CIRIEC nas quatro grandes linhas dos estudos actualmente desenvolvidos: contribuição dos serviços de interesse geral para a coesão económica, social e territorial, metodologia para o desenvolvimento de uma conta satélite das empresas de economia social, conceitos de economia social e comparação no seio dos estados-membros da União Europeia e situação dos serviços sociais e de saúde na União Europeia.

$\mathrm{Na}$ secção "Publicações" fica-se a saber que o CIRIEC publica uma revista científica, os Annales de l'Économie Publique Sociale et Coopérative/Annals of Public and Cooperative Economics, criada em 1908, e que os resultados da investigação levada a cabo pela sua rede científica são publicados regularmente sob a forma de obras colectivas, relatórios ou working papers devidamente listados na secção. O CIRIEC edita ainda uma nova colecção intitulada Economia Social \& Economia Pública (pela Peter Lang) e distribui por quem esteja interessado um boletim de informação trimestral intitulado CIRIEC-News.

\section{Título do sítio electrónico: Grupo de Pesquisa em Economia Solidária do Programa de Pós-Graduação em Ciências Sociais da Universidade do Vale do Rio dos Sinos (UNISINOS) URL: http://www.ecosol.org.br/}

Esta página pertence a um dos mais importantes grupos de investigação sobre Economia Solidária no Brasil, liderado por Luiz Inácio Gaiger, Professor na UNISINOS, e pretende divulgar os resultados da pesquisa feita pelo Grupo ou por outros. Ela está particularmente orientada para estudantes e pesquisadores, a quem oferece informação abundante sobre textos, fontes bibliográficas, livros e links.

A página de entrada destaca as novidades e, no momento actual, anuncia um importante Encontro Internacional organizado pelo Grupo e a realizar em Dezembro de 2009 sobre "A Economia Social e Solidária em Perspectiva Internacional" com a colaboração das Redes Internacionais de pesquisa RILESS (Rede de Investigadores Latinoamericanos de Economía Social y Solidaria) e a EMES Research Network. Quem procura informação académica sobre o tema e está a desbravar um campo novo encontra decerto nesta página muitas referências úteis, pois o grupo organiza também um programa de estudos pós-graduados, em que a página funciona como 
uma plataforma de informação. Referências que vão desde as apresentações feitas em encontros científicos por membros do Grupo (vd. link "Apresentações"), até uma ampla lista de textos relacionados com Economia Solidária, organizados por temas (vd. link "Bibliografia"), passando ainda por um rico elenco de livros básicos sobre Economia Solidária, apresentados de uma forma concisa ( $v d$. link "Livros"). Quem pretende saber mais sobre a actividade científica do Grupo e, particularmente, sobre a pesquisa realizada ou em curso, pode obter resposta no link "Pesquisa". Ficará a saber que após um primeiro período em que o investimento foi muito grande na análise da teoria e práxis da Economia Solidária no Brasil, o qual culminou com a realização de um estudo sobre o perfil dos Empreendimentos Económicos Solidários no Rio Grande do Sul a partir dos dados do Primeiro Mapeamento Nacional dos empreendimentos solidários no Brasil, os investigadores do Grupo têm vindo a alargar o âmbito dos seus estudos por forma a abarcar questões como a das identidades e das representações nos empreendimentos solidários, a dos critérios e padrões de eficiência nestes empreendimentos, ou a do microempreendedorismo solidário e do associativismo.

Finalmente, as ligações sugeridas pela página transportam o utilizador às principais instituições de referência para quem se ocupe do tema da Economia Solidária e esteja particularmente interessado na riquíssima experiência Brasileira.

\section{Título do sítio electrónico: Campus Virtual de Economia Solidária URL: http://www.economiasolidaria.net/}

O Campus Virtual é antes de mais um espaço de autor. Criado por Luís Razeto Migliaro, Professor da Universidade Bolivariana de Chile e ao mesmo tempo um activista da Economia Solidária, o Campus Virtual desempenha um papel importantíssimo como espaço de intercâmbio de obras, de experiências e de notícias e um espaço de contactos e diálogos sobre a Economia Solidária.

Orientado para estudantes, professores ou activistas da economia solidária, o site constitui um espaço diferente de estudo, leitura e reflexão, de conhecimento e troca de experiências e notícias, de investigação e aprendizagem, de contactos e diálogos, fornecendo muitas pistas úteis para o conhecimento do tema. Há guias de leitura, informações sobre autores que tratam do tema além de outros interessantes recursos. Os livros e artigos de Luis Razeto podem ser encontrados e baixados do site.
A página de entrada mostra imediatamente a postura inovadora e desafiante quanto à hierarquia das abordagens do tema, colocando num espaço circular arbitrariamente ordenado (ou melhor, deixando ao utilizador escolher livremente essas abordagens) um conjunto de entradas que o levam ao tema central da Economia Solidária. Se escolher a entrada "Foros", basta o registo para poder participar de debates sobre temas de interesse geral, como o da crise energética, exprimindo aí as suas ideias, opiniões e experiências. Se optar pela entrada "Consultas e diálogos", Luís Razeto estará disponível para responder a perguntas e a estabelecer diálogo sobre os conteúdos dos seus livros e artigos. Se escolher "Caleidoscópio" o utilizador depara-se com uma miscelânia de diferentes materiais - poemas, citações, humor, informações, etc. - que, de algum modo, "contribuem para pensar as temáticas do Campus 
e relacioná-las com outras dimensões da vida humana".

A preocupação formativa de um autêntico campus universitário está patente na disponibilização de preciosos materiais de estudo, como os "guias de leitura e de estudo" organizados por temas e em função dos niveis de conhecimento e motivações dos utilizadores: a saber, Guia de significados e termos da teoria económica compreensiva, As Microempresas, Ecologia e meio ambiente, Troca, reciprocidade, moeda local e dinheiros alternativos (link "Guias de leitura e de estudo"). Adicionalmente, um link leva-nos ao progama de Mestrado em Economia Solidária e Desenvolvimento Sustentável oferecido pela Universidade Bolivariana de Chile e coordenado por Luís Razeto.

Em "Testemunhos e experiências" é o conhecimento prático que se valoriza. Aí se depositam os testemunhos daqueles que estão envolvidos em projectos de acção, em empreendimentos de economia solidária ou em organizações de apoio, como os participantes das Feiras de Consumo Familiar de Barquisimeto (Chile), conhecidas como sítios de venda de comida barata, os membros do Grupo Red de Economía Solidaria (GRES), que promovem a formação de redes locais de economia solidária no interior do Perú, ou os filiados na CNT de Gipuzkoa, que trabalham ou trabalharam em empresas nascidas da chamada Experiência Cooperativa Mondragón.

Finalmente, nas secções "Bibliografia" e "Biblioteca de autores" o utilizador encontra uma vasta lista de referências sobre o tema da economia solidária.

Pedro Hespanha 